\title{
ИСПОЛЬЗОВАНИЕ СРЕДСТВ ИНФОРМАТИЗАЦИИ В ПРОЦЕССЕ ПОДГОТОВКИ ПЕДАГОГОВ ДЛЯ РАБОТЫ С ОБУЧАЮЩИМИСЯ С ОВЗ
}

\section{USING INFORMATIZATION DEVICES IN THE PROCESS OF TRAINING TEACHERS TO WORK WITH STUDENTS WITH DISABILITIES}

N. Kharchenko A. Izmailov I. Bagdasarova A. Eferova N. Pauzin

Summary: The rapid dissemination of information and the high level of informatization of all spheres of human activity determines the rapid development and use of modern information and communication technologies (ICT). Successful use of ICTs can only be ensured by those members of society who possess the necessary knowledge, skills and abilities that allow them to practically interact in the information space, quickly adapt to modern information and communication tools, that is, have an information and technological culture to ensure their own and professional needs. The ability to quick, efficient and effective work with information becomes important using modern means and methods.

Keywords: inclusive education, information and communication technologies, information space.
Харченко Николай Леонидович старший преподаватель, Московский государственный институт физической культуры, спорта и туризма имени Ю.А. Сенкевича m-rh@mail.ru

Измайлов Антон Зелимханович

К.филол.н., Московский авиационный институт (национальный исследовательский университет) arolan705@yandex.ru

Багдасарова Илона Юрьевна старший преподаватель, Московский физикотехнический институт (национальный исследовательский университет) artameli@mail.ru

Еферова Аделя Рафиковна

К.n.н., доцент, Российский экономический университет им Г.В. Плеханова earkov@list.ru

Паузин Николай Викторович

Преподаватель, Московский авиационный институт (национальный исследовательский университет) pauznick@mail.ru

Аннотация: Быстрое распространение информации и высокий уровень информатизации всех сфер человеческой деятельности обусловливает стремительное развитие и использование современных информационно-коммуникационных технологий (ИКТ). Успешное использование ИКТ могут обеспечить только те члены общества, которые обладают необходимыми знаниями, умениями и навыками, которые позволяют практически взаимодействовать в информационном пространстве, быстро адаптироваться к современным информационно-коммуникационных средствам, то есть обладают информационно-технологической культурой для обеспечения собственных и профессиональных потребностей. Важным становится умение оперативно, эффективно и качественно работать с информацией, используя для этого современные средства и методы.

Ключевые слова: инклюзивное образование, информационно-коммуникационные технологии, информационное пространство.

зовательного процесса, открыв доступ к обучению тем, кто ранее не имел такой возможности [6]. По мнению О.А. Козлова, всесторонняя информатизация влечет за собой интеллектуализацию многих видов трудовой деятельности и соответствующее повышение требований к профессиональной подготовке специалистов, уровню их информационной культуры [4, с 47].

Широкое использование информационно-коммуникационных технологий (ИКТ) и интерактивных муль- 
тимедиа, упрощенный доступ к глобальным сетям, в частности, Интернет, позволяет утверждать, что:

- процесс обучения становится независимым от физического расположения его субъектов;

- количество и разнообразие ресурсов, доступных ученикам / студентам во внеурочное время существенно возросла;

- локус контроля в инициации учебного процесса отошел ученикам / студентам: они сами способны инициировать процесс в любое удобное для них время, в любом месте.

Задача подготовки будущих педагогов к работе в инклюзивных образовательных организациях с обучающимися с ограниченными возможностями здоровья (ОВ3) определяется требованиями современного общества к подготовке специалистов в условиях информационного общества (среды) [5]. Требует особого внимания подготовка будущих квалифицированных педагогов для работы с обучающимися с особыми образовательными потребностями в направлении использования информационно-коммуникационных технологий в профессиональной деятельности, уровень их информационно-технологической культуры, что характерно как для технических специальностей, так и для гуманитарных [7, с. 137], в частности, обучению иностранным языкам [9, с. 149].

Следует также обращать внимание на психоэмоциональный статус обучающихся [10, с. 150]. Данное явление апробируют некоторые ученые [12, с. 207]. Именно психоэмоциональный статус влияет на адаптацию к стрессу и успеваемость обучающегося [14, с. 360] и устойчивое развитие $[15$, с. 6420].

Уровень информационной компетентности будущего педагога способствует успешной его адаптации в образовательной организации, и гарантирует овладение эффективными методами и средствами сбора, накопления, обработки и передачи информации в течение всей профессиональной деятельности [13, с. 3747].

По нашему мнению, развитие информационнотехнологической культуры педагогов зависит от информационно-методического обеспечения учебного процесса, эффективного использования педагогом профессионального обучения современных педагогических и информационных технологий, системного взаимодействия между педагогом, учениками и средствами ИКТ, уровня их культуры использования ИКТ в профессиональной деятельности, то есть созданной информационного учебной среды.

Бесспорно, интеграция ИКТ в процесс подготовки будущих педагогов к работе в сфере инклюзивного об- учения способствует оптимизации педагогической системы. Отметим, что новые условия профессиональной деятельности требуют активного внедрения современных технологий в учебный процесс и эффективного их использования, соответственно, и существенных изменений в содержании, методах и приемах обучения, способах разработки дидактических материалов.

Успешное внедрение ИКТ в учебный процесс с целью повышения его качества детерминировано информационной культурой всех участников образовательного процесса. Использование информационных и коммуникационных технологий в образовательном процессе неизбежно ведет к изменениям содержания обучающих программ, материально технического обеспечения образовательных организаций, уровня профессиональной культуры педагогов профессионального обучения. Возникает потребность в обновлении комплексно-методического обеспечения дисциплин, средств обучения, готовности педагогов к использованию в своей деятельности новых технологий обучения, которые, в свою очередь, требуют от педагога постоянного самообразования. Необходимость широкого использования современных компьютерных средств, информационно-коммуникационных технологий в учебном процессе является неоспоримым фактом.

Будущий педагог, обучающийся осуществлять свою профессиональную деятельность в сфере инклюзивного образования должен адаптироваться к новым информационным технологиям, интегрироваться с современными потребностями профессионального образования, эффективно выбирать и использовать именно те информационные технологии, которые способствуют достижению поставленной цели, тем самым постоянно повышая свою профессиональную культуру. Без качественного роста педагогического профессионализма будет невозможно достичь главной цели - получения качественного образования всеми членами общества. В связи с этим актуальным является обучение, основанное на применении ИКТ, то есть использование педагогом современных информационных и коммуникационных технологий.

Как показывает образовательная практика, ИКТ являются обязательной составляющей профессионального мастерства и требует должного внимания в процессе профессиональной подготовки любого специалиста, в том числе будущего педагога для работы с обучающимися с ОВ3. Учитывая это, создание эффективной системы развития информационной культуры будущего квалифицированного педагога чрезвычайно актуален.

С внедрением ИКТ в систему профессионального образования стала актуальной проблема разработки и 
использования новых форм и методов представления учебного материала, которая предусматривает совершенствование и видоизменение традиционных форм организации учебного процесса. Обычно на уроках и практических занятиях используются такие наглядные средства обучения, как доска и мел, плакаты и схемы, но данное представление информации статическое и усваивается гораздо хуже, чем визуализированный материал, представленный на экране компьютера, интерактивной доске и тому подобное.

Использование информационно-коммуникационных технологий в процессе обучения будущих педагогов дает возможность повысить наглядность обучения за счет использования различных форм представления учебного материала (текст, графика, рисунки, диаграммы, таблицы, аудио -, видеоматериалы и т.д.) [1; 3; 8; 11]. Кроме того, применение компьютерной техники позво- ляет совместить технические возможности современных информационно-коммуникационных технологий в представлении учебного материала как живого общения педагога с обучающимся, так и организации его самостоятельной работы и др.

Современные средства ИКТ, формы и методы подачи информации помогают создать и реализовать такое комплексно-методическое обеспечение программ подготовки будущих педагогов, которое будет способствовать развитию у них информационной культуры, с оптимальным выбором для каждого участника образовательного процесса (преподавателя или обучающегося) темпа изучения учебного материала, обеспечение индивидуальных потребностей обучающихся. Также при использовании современных ИКТ происходит существенная экономия времени, что в дальнейшем отражается на скорости усвоения учебного материала.

ЛИТЕРАТУРА

1. Вареницина Г.Г., Удалова И.П. - Использование интерактивных технологий в развитии связной речи у детей с ОВЗ в соответствии с ФГОС. В сборнике: Материалы конференций ГНИИ «НАЦРАЗВИТИЕ». Октябрь 2016. Сборник избранных статей. Ответственный за выпуск Л.А. Павлов. 2016. С. 51-54.

2. Еферова А.Р., Варфоломеева Н.С. Факторы формирования готовности к профессиональной мобильности в современных условиях образования // В сборнике: Ученые записки Ульяновского государственного университета. Актуальные проблемы лингвистики и преподавания лингвистических дисциплин. Сер. «Лингвистика». Факультет лингвистики, международных связей и профессиональной коммуникации Института международных отношений Ульяновского государственного университета. Ульяновск. 2017. С. 160-164.

3. Калинина Г.Н. - Применение современных инновационных технологий в организации образовательного процесса и обучении детей с ОВЗ. В сборнике: Педагогическое пространство: обучение, развитие, управление талантами. материалы международного заочного педагогического форума. 2016. С. 17-20.

4. Козлов 0.А., Ундозерова А.Н. Информационная культура личности в контексте развития современного информационного общества // Человек и образование. 2017. №4 (53). - С.46-52.

5. Кузьмина 0.С. Актуальные вопросы подготовки педагогов к работе в условиях инклюзивного образования // Вестник Омского Университета. 2013 . № 2. C. 191-194.

6. Нифонтова А.А., Гаршина Е.И. Социализация детей с ОВЗ в условиях инклюзивного образования. // Новая наука: Проблемы и перспективы. 2016. № 115-3. C. 74-77.

7. Сафонов М.А. Использование современных технологий в изучении модальных значений китайского языка // Сборник статей Всероссийской научнопрактической конференции Московского государственного технического университета (МИРЭА) “Инновационные технологии в образовании и бизнесе”. 2018. C. 137-141.

8. Сиско Н.О. Использование невербальных средств общения в коррекционной работе с детьми с ОВЗ. // Современные образовательные технологии в мировом учебно-воспитательном пространстве. 2016. № 9. С. 51-55.

9. Усов С.С. Использование современных технологий в изучении лексики английского языка // Сборник статей Всероссийской научно-практической конференции Московского государственного технического университета (МИРЭА) “Инновационные технологии в образовании и бизнесе”. 2018. С. 149-152.

10. Утюж А.С., Загорский В.А., Юмашев А.В., Нефедова И.В., Лушков Р.М. Оценка психоэмоционального статуса и анализ уровня тревожности у студентов первого курса медицинского университета. // В сборнике: Роль науки в развитии общества. сборник статей Международной научно-практической конференции: в 2-х частях. 2016. С. 148-157.

11. Шибаева М.Н. Рабочая программа коррекционно-развивающихся занятий для обучающихся с ОВЗ в соответствии с ФГОС ОВЗ (ЗПР) - Приоритетные направления развития науки и образования. Сборник материалов Международной научно-практической конференции. 2018 г. С. 101-103.

12. Юмашев А.В., Утюж А.С., Адмакин 0.И., Севбитов А.В., Нефедова И.В. Роль психогенных коннотаций в формировании эмоционального статуса студентов стоматологического факультета и пути его коррекции // Азимут научных исследований: педагогика и психология. 2017. Т. 6. № 2 (19). С. $207-210$.

13. Golubovskya E.A., Arkhipov S.V., Arupova N.R. The Role and Place of Teaching for an International Examination in a Foreign Language Course at a University // 11th International Conference of Education, Research and Innovation (ICERI2018). conference proceedings. 2018. IATED Academy. P. 3747-3753. D0I: 10.21125/ iceri.2018.1834. 
14. Yumashev A.V., Admakin 0.I., Utyuzh A.S., Doroshina V.Yu., Volchkova I.R. Effect of mesodiencephalic stimulation on adaptation to stress and academic performance of students. // International Journal of Learning and Change. 2018. T. 10. № 4. C. 359-367.

15. Zhang, T.; Shaikh, Z.A.; Yumashev, A.V.; Chłąd, M. Applied Model of E-Learning in the Framework of Education for Sustainable Development. Sustainability, 2020, 12, 6420.

\section{○ Харченко Николай Леонидович (m-rh@mail.ru ), Измайлов Антон Зелимханович (arolan705@yandex.ru),} Багдасарова Илона Юрьевна (artameli@mai.ru ), Еферова Аделя Рафиковна (earkov@list.ru ).

Паузин Николай Викторович (pauznick@mail.ru).

Журнал «Современная наука: актуальные проблемы теории и практики»

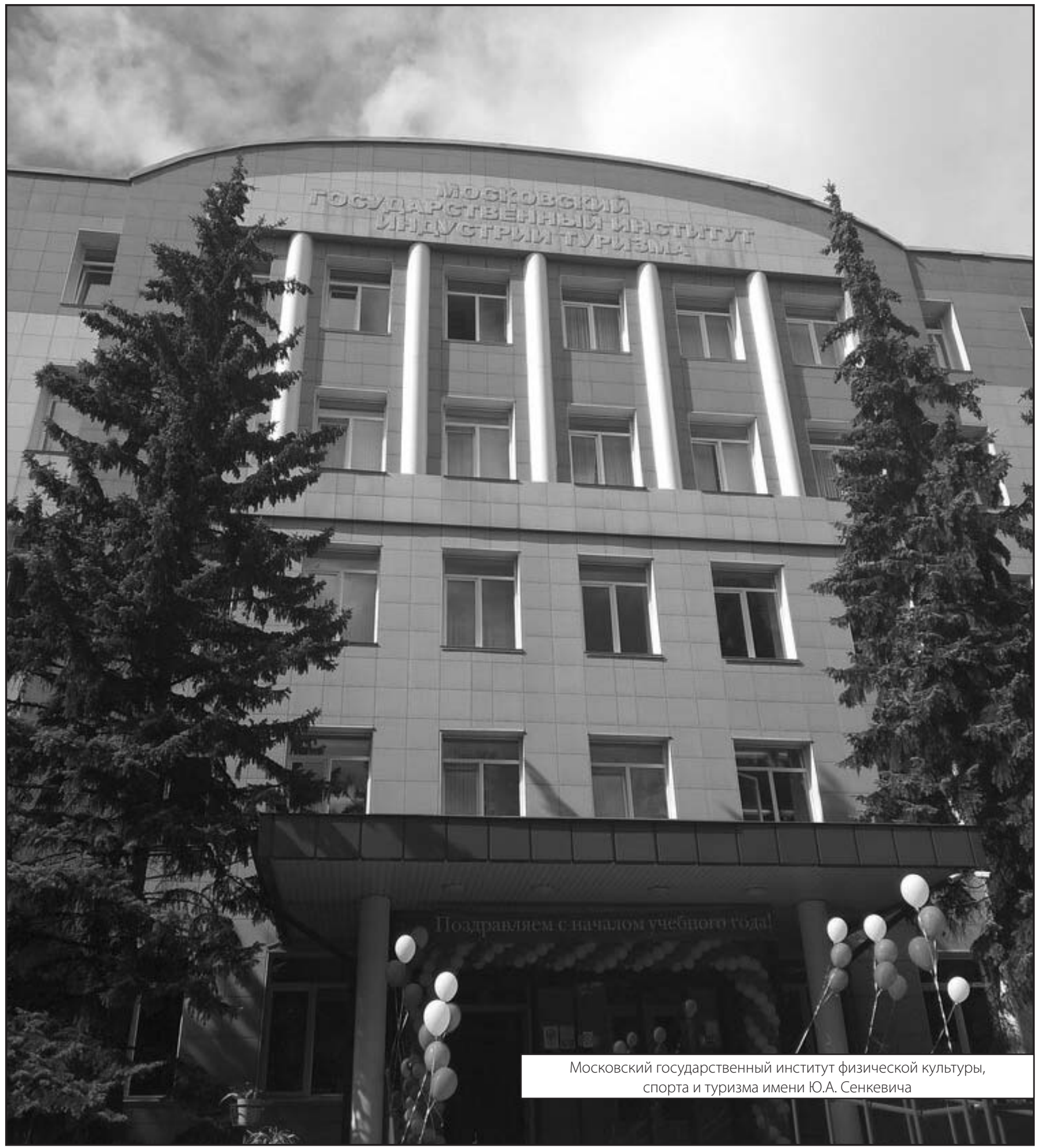

